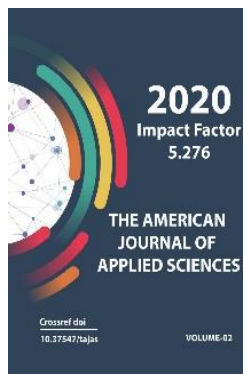

Journal Website: http://usajournalshub.c om/index,php/tajas

Copyright: Original content from this work may be used under the terms of the creative commons attributes 4.0 licence.

\section{Some Results Of Complex Interpretation Of Earth Remote Sensing Materials}

Nurkhodjaev Anvarbek Korakhodjaevich

Department Of Geodynamics And Tectonics, Dsc Professor, National University Of Uzbekistan Named After Mirzo Ulugbek, Tashkent, Uzbekistan

Togaev Isamiddin Safarovich

Department Of Geology, Teacher, National University Of Uzbekistan Named After Mirzo Ulugbek, Tashkent, Uzbekistan

Ibragimov Rustam Kholikulovich

Department Of Geodynamics And Tectonics, Teacher, National University Of Uzbekistan Named After Mirzo Ulugbek, Tashkent, Uzbekistan

\title{
ABSTRACT
}

We considered the principles of visual and automated interpretation of remote sensing data. The requirements for the creation of distance bases of different scale are set forth. The main areas of application of space imagery materials in regional stadies for solving applied geology problems are proposed.

\section{KEYWORDS}

Remote Sensing Data, Space Images, Deciphering, Remote Bases - Cosmogeogological Maps.

\section{INTRODUCTION}

The development of modern geological prospecting production can not be presented without new technologies and developments that allow obtaining new information serving as a criterion for estimating prospective areas and allowing local forecast of ore content with minimal costs. One of such directions is the use of (RSD) for solving applied and scientific-thematic problems of geology. 


\section{MATERIALS AND METHODS}

RSD materials carry objective information that allows mapping geomorphological indicators of structural forms formed as a result of thте action of endogenous and exogenous processes and the deepest buried structures in combination with geophysical data.

The technique of deciphering geological objects in images is the detection, recognition and interpretation (interpretation) of an object or phenomenon on the basis of certain criteria. At the present stage, the methods of using RSD materials for studying the geological nature of mountain and foothill areas have been developed and successfully introduced into geological exploration. A great deal of experience in the field of geoscientific research in different mining regions has been accumulated, the survey time, the range of the spectrum and the scale range of the most suitable for solving the problems of applied geology have been experimentally established. With the advent of digital imagery, the work performed on the basis of ERS materials was of a completely different nature and is widely used at regional and local levels of geological research. Naturally, along with this, the possibilities of using remote sensing materials have been greatly expanded and the geological decoding technique has been substantially improved.

However, the change in the vector of the direction of search and evaluation works towards areas hidden by soil and vegetation cover, loose sediments (sedimentary cover), requires completely different criteria, based on modern software tools, to analyze remote sensing data with the use of geological, geophysical and geochemical data for the study of closed areas and detection of potentially promising "blind" geological structures at depth. This is one of the priority areas of modern geology.

The advantage of the remote basis, the cosmogeological map, is that it explains the geology of the area from a new perspective and helps to identify elements that are not distinguished by other methods. The main geological units allocated to remote sensing materials are linear and ring structures, structurally-diffractive complexes (KFOR), which form the framework of the endogenous structure of the investigated territory, which is the basis for the compilation of geological, cosmogeological and other maps of the new generation [1].

With the advent of the possibility of obtaining digital photo images of the Earth, a new era of using space survey materials (SSM) to create remote bases - cosmogeological maps.

The creation of a remote base - a geologic map includes several basic methods of comparing and comparing objects within a single image and their logical interpretation (visual and automated). When creating a remote basis of the Republic of Uzbekistan on a scale of 1: 500 000, RSDs were used to solve the following tasks:

- Allocation of area and linear geological structures - complexes and their boundaries (structurally deciphered complexes);

- Study of structural-tectonic elements (faults, tectonic blocks, zones of crushing, fracturing, ring and fold structures, etc.);

- Complexing of cosmogeological, geophysical and geochemical data in the environment of GIS projects;

- Mineragenic zoning, identification of regularities in the location of minerals 
and forecasting of potentially promising areas (separate blocks).

The solution of these problems was carried out on the basis of space images Landsat 7, Aster (TERRA), Quick Bird and radar satellite imagery SRTM on the basis of ERDAS Imagine and ENVI software.

The deciphering of remote survey materials was carried out in three stages: preliminary, field (verifying) and final (2). In the preliminary stage, the systematization and processing of space survey materials were carried out. Based on the results of the analysis of factual data, taking into account geological, geophysical, geochemical and other information, a preliminary deciphering scheme was created, with isolated area, linear and concentric elements of the landscape. All identified elements in the preliminary decoding scheme were refined during the field-verification studies. The final processing of the received information was carried out during the office period. It includes the additional study of different-scale images on the nodal areas of the area, the linkage of the results of interpretation with geological observations, geophysical fields and geochemical anomalies; Correction of maps, schemes, tables of deciphering signs, criteria for the forecast of minerals.

\section{RESULTS AND DISCUSSIONS}

The main deciphering signs in the determination of area and linear geological structures and the separation of the boundary of the KDK in terms of the composition of rocks are the pattern and structure of the color gamut (spectral brightness) of the studied territory. The structure of the picture and the spectral brightness of the object in this case depends on the physical-mechanical, chemical properties, mineral composition, textural and structural features of the rocks, and also on the geological structure and geographical conditions of the territory (Figure 1). 


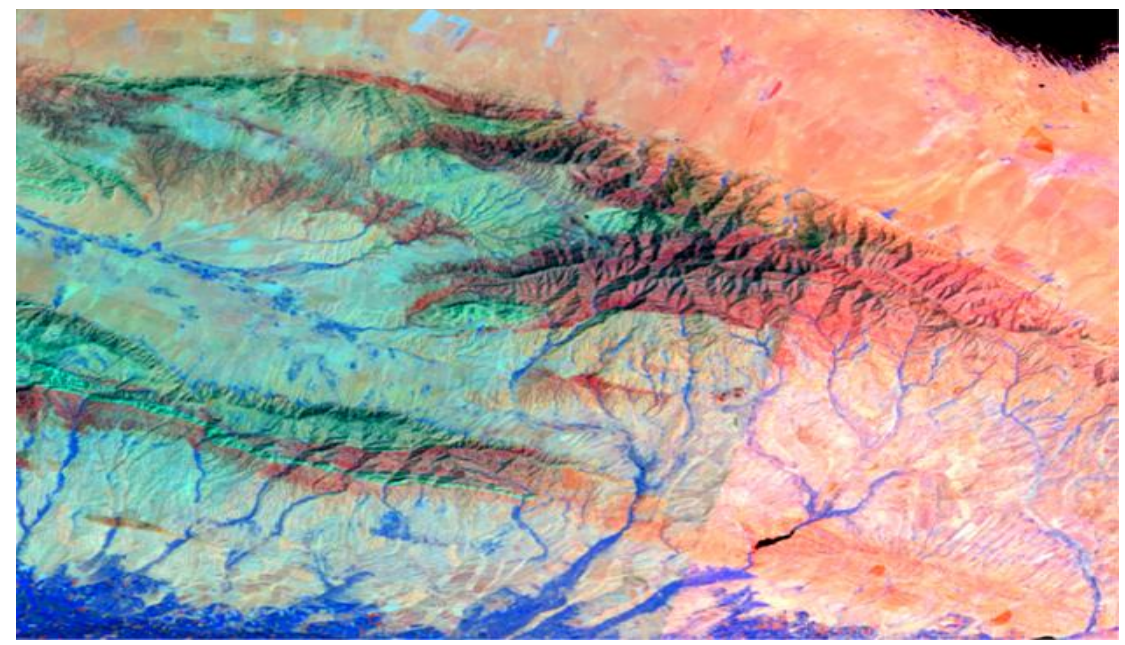

Figure1. Area and linear structures based on drawings and color anomalies on RSD materials, Western Uzbekistan.

Based on the recognition of various geological structures on the materials of space surveys, the preliminary distances are compiled according to the above-mentioned signs

(Figure 2).

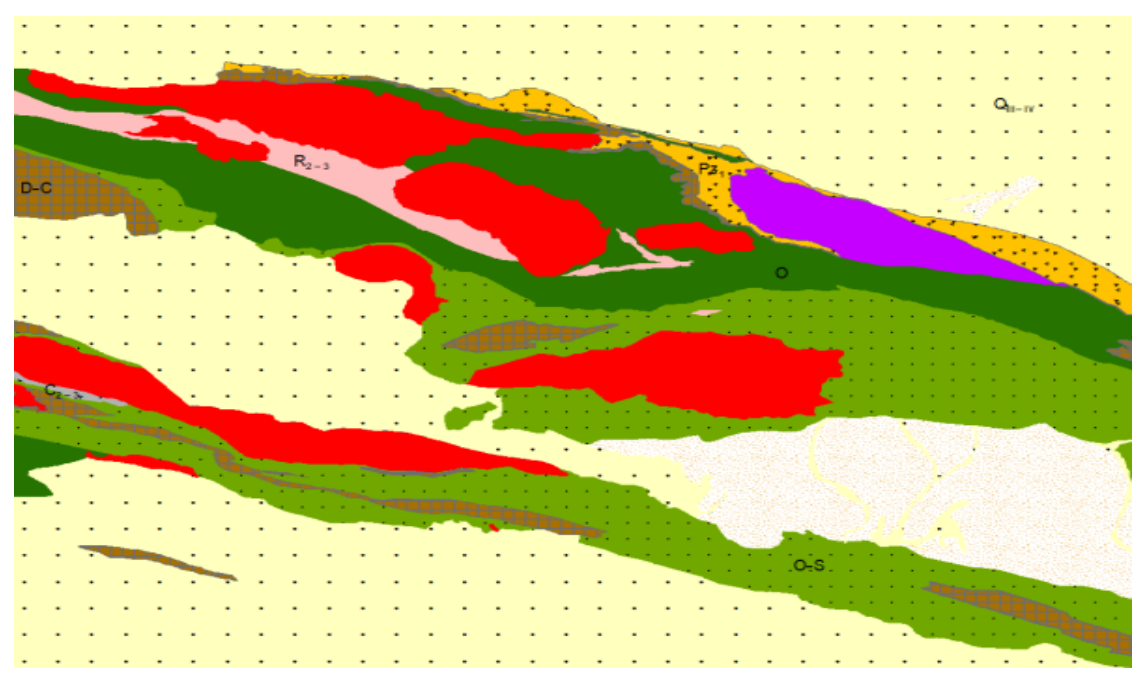

Figure 2. Results of interpretation (preliminary) RSD materials, Western Uzbekistan. 
When creating a preliminary remote bases for interpretting the materials of the Earth's surface, many natural and man-made factors, such as transparency of the atmosphere, type of relief, the density of vegetation, the availability of settlements, land cultivation , and so on. The deciphering of the territory with the meso-cainazoik cover was hampered by the density of vegetation cover, where there was technogenic appearance of geometric areas. In such cases, indirect landscape models of geological structures.

Useful and diverse geological information is extracted when deciphering space images of disruptive disturbances. Various elements of disjunctive tectonics appear on the materials of remote sensing of the earth's surface in the form of lineaments. Despite the age-old history of using this concept in the study of the deep structure of the Earth, there is still no single concept of "lineament", there are several concepts. Nevertheless, in all definitions there is much in common. Under the lineaments understand straight or slightly curved natural features of the landscape often displaying linear inhomogeneity of the lithosphere, namely the faults of the crust, flexure in the sedimentary cover, the zone of sharp changes of geological structures, separation in one line of geochemical anomalies and high-gradient zones of geophysical fields [1-3] .

The final stage of creating the remote basis is post-field dehiviriation of RSD materials, which will use the results of visual and automated interpretation, field verification materials, integration with geophysical and geochemical data of the studied area. As a result of the analysis of all available materials, the final version of the remote framework will be created.
The remote basis is a constructive, projectoriented document that can be used for planning and performing works, allows generalizations, long-term and retrospective analysis of geological and geophysical materials, study of regularities in the location of mineral resources and facilitates the rational placement of prospecting within the recommended forecast sites. Naturally created a new document has a specific nature and the requirement for it is special.

The authors of this article developed the basic requirements for compiling a distance basis of various scales. They are set out in the monograph "Methodological guidelines for compiling the cosmogeological map of the Republic of Uzbekistan on the basis of digital space images" (Nurkhodzhaev AK and others 2017y).

Experience shows that the most informative, from the point of view of accuracy and efficiency of solving geological problems, are digital distance bases of scale 1: 200000 and 1: 50000 (in individual areas up to $400 \mathrm{~km} 2$ ). These scales correspond to the tasks of the regional work on ground verification of decryption data at scale levels, namely: scale 1: 500000, provides operational planning within the ore province; scale 1: 200000, provides geological exploration planning and assessment of their condition within the mining area; scale 1: 50000 - provides geological exploration planning and assessment of their condition within the ore field and a separate field.

Estimating the role of remote sensing materials in the creation of a remote basis, it should be noted that this method, especially in combination with geophysical, geochemical, geomorphological methods, is used to solve all the basic tasks that geologists face in geological regional operations. Based on the 
materials of space surveys, the geological structure of the territory was specified, new information about the localization and structure of mineral objects, as a zone of

\section{REFERENCES}

1. Borisov OM, Glukh AK. Ring structures and lineaments of Central Asia. - T .: 1982.123.

2. Kats YG, Ryabukhin AG, Trafimov DI Cosmic methods in geology.-Moscow: Izd-vo MGU, 1976, p.248.

3. Nurkhodzhaev AK Modern state and prospects of development of remote sensing of the Earth in the field of geological prospecting of the Republic of Uzbekistan. Geology and mineral resources.-2017.-No.1-P.78-83.

4. Nurkhodzhaev AK, Togaev IS, Shamsiev RZ. Methodological guidelines for compiling a cosmogeological map of the Republic of Uzbekistan on the basis of digital space images. Tashkent. 2017. 200 s.

5. Snitka NP, Khamroev I.O. The connection of geodynamics with the metallogeny of the Southern Tien Shan and the actual tasks of conducting geological exploration work. Geodynamics, magmatism and mineralization of the Western Tien Shan.Materials of the scientific conference dedicated to the 8oth anniversary of Academician TNDalimov. 2016. P.105-109.

6. Ergashev Sh.E., Isahodjaev BA, Avezov A.R. New in the technique of using the materials of space imagery in solving geological problems // Mat. Scientific and practical conference. "Space research, technology and conversion." Ed. regional fracturing, detection of buried intrusions (especially the apical part) and linear types (5) was specified.

\footnotetext{
"Uzbekcosm", Tashkent, 1997.-With 6062.
}

7. W.G. Rees. Physical principles of Remote Sensing. Cambridje University Press. 2001.335p. 